\title{
Conservación de bienes culturales: acciones y reflexiones,
} una mirada a la conservación en México

\author{
Olga Lucía González Correa
}

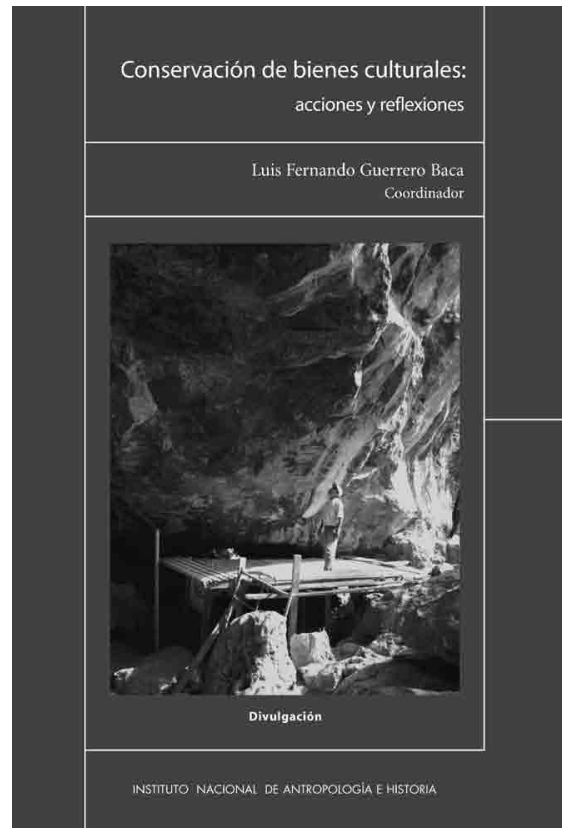

Luis Fernando Guerrero Baca (coord.) Conservación de bienes culturales: acciones y reflexiones, México, INAH, Divulgación 2009.

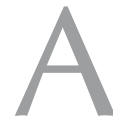

brir el libro publicado por el Instituto Nacional de Antropología e Historia (INAH) Conservación de bienes culturales: acciones y reflexiones ofrece a quien lo hace un amplio abanico de posibilidades de lectura, desde la revisión misma de su índice. Se trata de una compilación de 17 escritos producidos por 22 profesionales de los cuales 20 están adscritos al INAH (15 en la Coordinación Nacional de Conservación del Patrimonio Cultural, tres en Centros Regionales, uno en la Escuela Nacional de Conservación, Restauración y Museografía y uno en la Biblioteca Nacional de Antropología e Historia), uno a la Facultad de Filosofía de la Universidad Panamericana y uno al Instituto de Física de la Universidad Autónoma de México.

Los autores dan cuenta de diversos temas y estudios de caso en el área de la conservación y protección del patrimonio cultural: tráfico ilícito de bienes culturales, conservación preventiva, materiales para la intervención, conservación y comunidad, conservación y restauración de retablos, patrimonio arqueológi$\mathrm{CO}$, arte rupestre, material etnográfico y obras gráficas y documentales.

Esta obra publicada dentro de una colección editorial de divulgación, cumple el importante fin de informar al público en general de qué se trata la disciplina de la conservación de bienes culturales que, si bien lleva décadas de ejercicio, crecimiento y desarrollo profesional, no es del todo conocida y reconocida socialmente. En este sentido, cada uno de los escritos, incluyendo la síntesis que presenta el coordinador de la publicación, ofrece un modelo de acción del conservador-restaurador actual, quien actúa con base en el escrutinio de los bienes culturales en sus diferentes facetas, utiliza para su estudio técnicas de análisis de diversas ciencias, plantea procedimientos con base en un diagnóstico, planea las actividades, propone metodologías, se plantea desarrollar trabajos a mediano y largo plazos, aborda el bien cultural como objeto vinculante, trasciende la intervención de la materia, define criterios de intervención focalizados, aborda el patrimonio en relación estrecha con la sociedad que lo alberga y, finalmente, lucha cada vez más por la prevención antes que la curación.

En el terreno de la divulgación, otra lectura valiosa de la obra es la sensibilización que ofrecen sus textos hacia la valoración del patrimonio como referente de identidad cultural y como fuente de información para la producción de conocimiento.

De manera indirecta pero no menos cierta, profesionales de otras disciplinas pueden encontrar en estos escritos caminos diversos de vinculación a la protección del patrimonio, pues en ellos es profusa la alusión a la necesidad del 
trabajo interdisciplinario y a cómo lograrlo en casos específicos de estudio y documentación de los bienes culturales. Es, si se quiere, una invitación a la academia y al mundo laboral para abrir nuevos frentes de investigación y de trabajo, para socializar la tarea de conservar el patrimonio cultural.

Aunque no se haga explícito como propósito editorial, internacionalmente este libro tiene el mérito de mostrar una manera de abordar el tema de la salvaguarda del patrimonio desde el Estado y pone en evidencia cómo México, exuberante en la posesión de bienes culturales de todos los tiempos y momentos de su devenir, ha construido dentro de sus instituciones instancias especializadas para su protección y difusión. Esto es especialmente relevante en América Latina, donde los países tienen mucho por aprender y por hacer. El INAH cuenta hoy en día con una Coordinación Nacional de Conservación del Patrimonio Cultural, producto del esfuerzo de muchos profesionales que han hecho crecer lo que en los años sesenta era un Departamento de Restauración del Patrimonio Cultural. Los trabajos expuestos en Conservación de bienes culturales: acciones y reflexiones, particularmente los desarrollados en los sitios arqueológicos, muestran un avance importante en materia de políticas de protección de los bienes culturales, en tanto se han planteado labores planificadas a mediano y largo plazos que van mucho más allá de las acciones coyunturales. Por otro lado es de destacar, también en los casos referidos a los sitios arqueológicos, la definición de principios que actualmente están guiando la intervención del patrimonio arqueológico y que pueden constituirse en un modelo a seguir en otros países que cuentan con bienes de esta naturaleza. $Y$ pueden ser referencia para acciones en otros lugares del mundo, porque ellos son producto del trabajo de protección de un vasto y complejo patrimonio arqueológico y de la reflexión en torno a una larga historia de aciertos y desaciertos en su intervención.

Como libro dedicado al tema de la conservación del patrimonio, los estudios presentados en él tienen especial interés para los profesionales del área, trascendiendo las fronteras de México. Y, no obstante ser un texto de divulgación que no ofrece un nivel profundo de especialización en la presentación de los estudios, el conservador-restaurador puede extraer de ellos información particular de procedimientos técnicos y uso de materiales de intervención, que podrían serle de utilidad al enfrentarse a casos similares en su quehacer, ya sea para aplicarlos, contrastarlos o revaluarlos. Puede, igualmente, deducir metodologías de acción en la planeación de su trabajo y desarrollar ideas de investigación sugeridas para la disciplina.

Entre las posibles lecturas que aquí se han sugerido y muchas otras que pueden darse, podría finalmente proponerse una que invita a abrir la discusión en torno a dos aspectos: uno, el concepto de conservación integral plasmado en varios de los escritos; y, otro, el perfil del restaurador en el marco de lo que se ha llamado en esta publicación conservación social o conservación con enfoque social.

Es claro que parte del desarrollo y consolidación de una disciplina como tal se ve reflejada en la definición de sus conceptos y en la especialización del lenguaje que le es propio. En varios de los textos compendiados en este libro, se habla de conservación integral, proyectos integrales, planes integrados; algunas veces haciendo referencia a la vinculación conservación-identidad-desarrollo, otras al trabajo interdisciplinario, y algunas otras a la planeación de diversas fases de la conservación y restauración al interior de un proyecto o de una institución. La recurrencia en el uso de estas expresiones sugiere la intención de crear una nueva categoría en la disciplina, que al utilizarla haga clara alusión a un tipo de acción. Si ello es así, sería conveniente realizar una puesta en común de este tema, con el fin de lograr consolidar un concepto que a todas luces implica una evolución en el ejercicio de la conservación.

Por último, es necesario revisar y discutir el perfil del conservador-restaurador en el marco de lo que se ha llamado conservación social. Indiscutiblemente, el uso de esta categoría muestra una tendencia de la disciplina al punto que en la Coordinación Nacional de Conservación del Patrimonio Cultural del INAH existe una Subdirección de Proyectos Integrales con Comunidades. No ha sido fácil definir y delimitar el perfil de este profesional, cuyo quehacer surgió como un trabajo artesanal, pasó por ser una dedicación proveniente del mundo de las artes, tuvo educación no formal y formal a nivel técnico y ha llegado en la actualidad a ser una actividad profesional basada en un cuerpo de conocimiento construido a partir de la interlocución con el saber de diversas ciencias. Si bien es fundamental y necesario considerar al patrimonio como una fuente $y$ un vehículo de desarrollo social y económico, también lo es establecer los límites y las pertinencias profesionales para potenciarlo como tal.

Sean estas palabras una invitación a la difusión, lectura y discusión del libro en cuestión, el cual es un aporte valioso nacional e internacionalmente. 